\title{
What makes deterrence credible?
}

\author{
Dr Andromachi Georgosouli*
}

\begin{abstract}
According to current orthodoxy deterrence is credible when it is visible and visibility calls for enforcement action that is harsh enough to be taken seriously so that it makes an impact on the behaviour of the industry. In this chapter, I argue that the focus on enforcement is misplaced because, when it comes to the question of 'credibility', at best it tells half the story. The credibility of deterrence is contingent to a multitude of factors. In this chapter, I consider three of them all of which are closely inter-related: The regulator's capacity to attain a congruence of 'minds' and a congruence of 'hearts' and the regulator's ability to harness its profile as a credible enforcer.
\end{abstract}

\section{Introduction}

According to current orthodoxy deterrence is credible when it is visible and visibility calls for enforcement action that is harsh enough to be taken seriously so that it makes an impact on the behaviour of the industry. ${ }^{1}$ In this chapter, I do not intend to doubt the role of enforcement in deterrence policy but to argue that the focus on enforcement is misplaced because, when it comes to the question of 'credibility', at best it tells half the story. The picture is far more complex because the credibility of deterrence is contingent to a multitude of factors. In this chapter, I consider three of them all of which are closely inter-related: The regulator's capacity to attain a congruence of 'minds' and a congruence of 'hearts' and the regulator's ability to harness its profile as a 'credible enforcer'.

It is a good time to consider this theme. In June 2015 IOSCO published a paper on 'Credible Deterrence in the Enforcement of Securities Regulation'. IOSCO identifies seven factors that make deterrence credible. These are the following: (a) legal certainty, (b) capacity of being able to get the right information, (c) co-operation and collaboration; (d) investigation and prosecution of misconduct; (e) strong punishment through the imposition of sanctions; ( $f$ ) promoting public understanding and transparency and $(\mathrm{g})$ good regulatory governance in order to deliver better enforcement. The IOSCO recommendations seem to be premised on the assumption that the credibility of deterrence can be strengthened as long as we can take measures to improve the effectiveness of enforcement. ${ }^{2}$ This paper warns that improvements on enforcement can actually have no positive impact on the credibility of deterrence. More generally, it is essential to keep in mind that the effectiveness of enforcement and the effectiveness of deterrence are not one and the same thing. The effectiveness of enforcement can be measured by the number of successful enforcement proceedings irrespective of whether enforcement inflicts behaviour modification. By contrast, deterrence is not successful unless there is some evidence of behaviour modification. In

\footnotetext{
*Dr Andromachi Georgosouli (a.georgosouli@qmul.ac.uk), Senior Lecturer, Centre for Commercial Law Studies, QMUL. I wish to thank ....for their feedback on earlier versions of this chapter. Any errors remain my own.

${ }^{1}$ See notably, G. Wilson and S. Wilson, 'The FSA, "Credible Deterrence, and Criminal Enforcement -a "haphazard pursuit"?' (2014) 21(1) 21(1) Journal of Financial Crime 4-28; and T. McDermot (acting director of the Enforcement and Financial Crime Division) 'Credible Deterrence: Here to Stay', FSA Speech (FSA Enforcement Conference; 2 July 2012) [available at http://www.fsac.org.uk/library/communication/speeches/2012/0702-tm.html].

2 IOSCO 'Credible Deterrence in the Enforcement of Securities Regulation' (June 2015) [available at: https://www.iosco.org/library/pubdocs/pdf/IOSCOPD490.pdf].
} 
view of this, the credibility of deterrence (and by implication its effectiveness) is to be measured in terms of how well the regulator actually does in attuning industry incentives with those of the regulator in the medium and long term.

For expository purposes, examples are drawn from the work of the Financial Conduct Authority (FCA) and where appropriate the work of the predecessor of the FCA, the Financial Services Authority (FSA) in deterring misconduct in the financial services sector. ${ }^{3}$ This chapter does not offer a comprehensive account of all those market, institutional, legal, behavioural and cognitive conditions that make deterrence credible and it does not provide all the answers. However, it highlights certain determinants of deterrence, which point to pathways for reform. Although the aim of this chapter is not to offer a critique of the IOSCO recommendations, its findings may help put the IOSCO recommendations in context and understand how these recommendations might be further refined in the future.

Deterrence studies go in hand with regulatory scholarship on enforcement and compliance focusing in particular on regulatory approaches that subscribe to the idea that 'prevention is better than cure' ${ }^{4}$ The aim of deterrence strategy is to dissuade market actors from breaching the law in the future, while at the same time preventing others from committing similar breaches. Over the years, these studies have been influenced by two schools of thought. On the one hand those who believe that market actors will comply with the law only when confronted with tough sanctions and, on the other hand, those who believe that persuasion works better in securing long term compliance. More recently, these strands of thought gave rise to hybrid accounts of deterrence strategies as it has been increasingly recognised that better results may be achieved when regulatory approaches combine elements of both. Hybrid strategies are considered to be pragmatic because the industry sometimes is motivated by making money and sometimes is motivated by a sense of social responsibility. ${ }^{5}$

The deterrence policy of the FCA combines both elements of punishment and persuasion, although more recently there is a clear emphasis of the FCA as an 'enforcement-led' regulator. ${ }^{6}$ More generally the idea of enforcement as the catalyst for credible deterrence is as powerful as never before finding also the official endorsement of IOSCO. Below, I put this view into test and, progressively, I bring attention to other factors that impact on the credibility of deterrence. I

\footnotetext{
${ }^{3}$ As of April 2013, the FSA was abolished and replaced by the Financial Conduct Authority ("FCA") and the Prudential Regulation Authority ("PRA"), the latter being a subsidiary of the Bank of England. The FCA and the PRA are focus-specific with a separate set of statutory objectives to deliver. They are operationally independent and at least on paper of equal institutional standing. The strategic objective of the FCA is to ensure that financial markets function well (Financial Services Act 2012 section 1B(2) (amending Financial Services and Markets Act 2000). To this effect, the FCA is responsible for consumer protection, market integrity, and competition in the interests of consumers (FSA 2012, sections 1B(2), 1(C), 1D, $1 \mathrm{E}$. The PRA is the primary micro-prudential regulator and part of its mandate is to offer a helping hand to the Financial Policy Committee of the Bank of England in delivering its financial stability objective (FSA 2012 section 2B ("The PRA's general objective"). See further, A Georgosouli, 'The FCA-PRA coordination scheme and the challenge of policy coherence', (2013) 8(1) Capital Markets Law Journal, pp. 62-76.

${ }^{4}$ For an overview of the literature on compliance and enforcement part of which is the theme of deterrence see, $\mathrm{B}$. Morgan and K. Yeung, 'An Introduction to Law and Regulation: Texts, Cases and Materials (Cambridge: Cambridge University Press; 2007) chapter 4 pages 151-217.

${ }^{5}$ Braithwaite, To Punish or Persuade: Enforcement of Coal Mine Safety (Albany: State University of New York Press, 1985) B. Morgan and K. Yeung, An Introduction to Law and Regulation: Texts, Cases and Materials (2007) at 194-195.

${ }^{6}$ R. Tomasic, (2011) 'The financial crisis and the haphazard pursuit of financial crime' (2011) 18(1) Journal of Financial Crime 7-31 (discussing the nature of the regulatory change by focusing on financial crime).
} 
conclude with a summary of the main points of this analysis and further reflections on the direction of future reform.

\section{Recent trends in the deterrence strategy of the Financial Conduct Authority (FCA)}

To understand the nature of the deterrence strategy of the FCA and, where relevant, of its predecessor the Financial Services Authority, it helps to draw a distinction between two different conceptions of deterrence: Positive deterrence and negative deterrence. The distinctive feature of positive deterrence is its emphasis on voluntary adherence with regulatory stipulations. The idea here is that prevention of misconduct is happening out the initiative of the industry and not as a result of coercion typically in the form of enforcement action instigated by the regulator. Positive deterrence comes in hand with forms of self-governance, ethics and business culture. ${ }^{7}$ Under this approach enforcement is not precluded but it is nevertheless seen as a necessary evil and as a means of last result when all other informal and voluntary avenues of remedial action have failed to secure some form of appropriate financial redress to aggrieved parties. Negative deterrence stands at the other side of the spectrum. Its distinctive feature of negative deterrence is its reliance on enforcement, its strong association with traditional command and control regulation and the view of the financial regulator as 'enforcement-led' regulator.

The UK regulator did not always give emphasis to negative deterrence strategies, however, more recently, there has been a consistent and deliberate endeavor to forge the profile of the UK regulator as enforcement led regulator. This started off as early as 2007, when the FSA launched its 'credible deterrence' strategy. This trend continues today by the FCA and it is manifested in two key developments. On the one hand, the granting of more enforcement and interventionist powers to the UK regulator and, on the other hand, the increase of disciplinary and enforcement actions.

At least on paper, the FCA enjoys a wider range of disciplinary and enforcement powers compared to its predecessor. ${ }^{8}$ The FCA has, inter alia, the power to (a) impose administrative fines, (b) withdraw authorisation and permissions, (c) apply for injunctions and restitution orders, and (d) prosecute certain criminal offences. ${ }^{9}$ In addition, the new section $138 \mathrm{D}$ (former section 150) establishes a civil law remedy for aggrieved parties to seek compensation. ${ }^{10}$ To ensure that the regulator's disciplinary action will be visible enough to have an impact on the conduct of market actors, new section 391 (1ZB) also enables the FCA to publish information about warning notices in

\footnotetext{
${ }^{7}$ H. Becker, 'Culture: A Sociological View' (1982) 71 Yale Law Review 513 (describing culture as shared understandings that permit a group of people to act in concert with each other); J. O'Brien, G. Gilligan and S. Miller, 'Culture and the Future of Financial Regulation: How to Embed Restraint in the Interests of Systemic Stability', (2014) 8(2) Law and Financial Markets Review 115-133 at 126 (identifying five sources of cultures); Jasper Sorensen, The Strength of Corporate Culture and Reliability of Firm Performance, (2002) 47(1) Administrative Science Quarterly 70-91 at 72 (offering a narrow definition of culture as a system of shared values).

8 See Financial Services and Markets Act, 2000, Part XI (Information Gathering and Investigations) and Part XIV (Disciplinary Powers) (as amended by the Financial Services Act 2012).

${ }^{9}$ See FCA, Enforcement Information Guide (2013) [available at http://www.fca.org.uk/your-fca/documents/enforcementinformation-guide].

10 Only "private persons" are eligible to make use of this statutory civil law remedy. See FSMA 2000 (Rights of Actions), 2001, S.I. 2001/544 (U.K.); Titan Steel Wheels Ltd. v. The Royal Bank of Scot. PLC, [2010] EWHC (Comm) 211, [76] (Eng.) (finding a corporation did not qualify to bring an action under section 150 of the original FSMA 2000 because it was acting in the course of business); Figurasin v. Cent. Capital Ltd., [2014] EWCA (Civ) 504 (Eng.).
} 
certain cases. ${ }^{11}$ Other key elements of the new strategy is the novel powers of product intervention. The availability of those powers may also be explained in terms of the endeavour of the legislator to improve the regulator's capability of deterring future misconduct. ${ }^{12}$ Product intervention powers are quite controversial but the regulator need not exercise these powers. Suffice is to demonstrate a serious intention to do this in the future in view of repeated industry failings to provide products that are suitable to their clients.

There is a notable increase of the rate of enforcement action over the past seven years. The imposition of record fines on Alliance and Leicester for serious failings in the selling of Payment Protection Insurance (PPI) back in 2007 has been a milestone underlying a notable change of attitude which was crystallized over the subsequent years. ${ }^{13}$ The GMAC is another case that offers a clear testament to this wind of change. ${ }^{14}$ So, it does the impressive volume of Final Notices, Decision Notices, the aggregate amount financial penalties imposed on individuals and firms and the number of prohibitions and criminal convictions during 2010 - 2012. ${ }^{15}$ More recently, the imposition of a record fine of $f 284 \mathrm{~m}$ on Barclays Bank plc has been celebrated as further cementing the role of the FCA as 'enforcement-led' regulator. ${ }^{16}$

These developments in the deterrence strategy of the FSA and more recently the FCA underscore the key role of enforcement in the delivery of credible deterrence. As the argument goes, heavy fines are expected to make a difference and to drive change in the financial services sector, however, the latest experience with the FCA casts doubt on the potency of enforcement in enhancing the credibility of deterrence. This is further explained below.

\footnotetext{
11 The FSA's use of these powers has already been challenged by way of judicial review and in the Upper Tribunal. See R ex rel. S v. X, [2011] EWHC (Admin) 1645, [4]-[10] (Eng.) (addressing the claimant's appeal of the FSA's decision notice to the Upper Tribunal and granting an interim injunction to restrain the FSA from publishing the notice); R ex rel. Can. Inc. v. FSA, [2011] EHWC (Admin) 2766 (Eng.).

12 Financial Services Act 2012, new section 137D (FCA general rules: product intervention), new section 137R (Financial promotion rules) new section $137 \mathrm{~S}$ (Financial promotion: directions given by the FCA). Some of the FCA's key priorities in respect to consumer credit reveal the intention of the UK regulator to make use of its new powers. These priorities include (a) the review of financial promotions, (b) the improvement of debt management standards, (c) considering the introduction of price caps on what payday lenders can actually charge, (d) assessing regularly how the industry treats financial difficulties, and (e) getting a better understanding of the economic behavior of consumers. FCA, Business Plan 2014/15 (2014) [available at http://www.fca.org.uk/static/documents/ corporate/business-plan-2014-2015.pdf.]

${ }^{13}$ A\&L was fined $£ 7,000,000$. Post crisis, financial firms were made to pay much higher fines. See FCA Press Release, FCA Fines Lloyds Banking Group First a Total of $£ 28,038,800$ for Serious Sales Incentive Failings (Nov. 12, 2013), [available at http://www.fca.org.uk/news/press-releases/fca-fines-lloyds-banking-group-firms-for-serious-sales-incentive-failings; Final Notice from Fin. Conduct Auth. to Lloyds TSB Bank plc and Bank of Scotland plc (Dec. 10, 2013) [available at http://www.fca.org.uk/your-fca/documents/final-notices/2013/lloyds-tsb-bank-and-bank-of-scotland.]

${ }_{14} \mathrm{GMAC}$ was a non-bank lender in the prime, sub-prime and buy to let mortgage sectors. The disciplinary action focused on failures with respect to MCOB and the proper implementation of TCF. The GMAC failings included excessive and unfair charges for customers; proposing repayment plans that were not suitable, and starting repossession proceedings before considering other alternatives. Apart from having to pay a fine of $£ 4$ million, like A\&L, GMAC agreed to carry out a customer regress programme. See FSA Final Notice GMAC-RFC Ltd (October 28, 2009) [available at http://www.fsa.gov.uk/pubs/final/gmac rfc.pdf] and further, Compliance Officer Bulletin Issue 76 May 2010.

15 T. McDermott (acting director of the Enforcement and Financial Crime Division), 'Credible deterrence: here to stay' FSA Speech (02 Jul 2012, FSA's Enforcement Conference) http://www.fsa.gov.uk/library/communication/speeches/2012/0702tm.shtml

16 The fines that were imposed on Barclays relate to the LIBOR scandal and in particular to the involvement of Barclays the Forex misconduct. M. Bonell, 'Is credible deterrence really working? And other questions arising from a mixed week for the FCA' (28 May, 2015) Financial Services Blog [available at http://www.rpc.co.uk/index.php?option=com_easyblog\&view=entry\&id=1518\&/temid=133].
} 


\section{Is enforcement making deterrence credible?}

A good starting point to consider this question is perhaps the experience with the imposition of the highest ever record fine upon Barclays Bank in 2015. It is interesting to note that many of Barclay's failures in relation to FOREX came after a time when it should have been aware of the risks from such business. Barclays continued to behave badly despite the fact that it had already paid a fine for a similar misconduct. Moreover, Barclays continued to misbehave while been subject to fresh investigations about its involvement to the LIBOR scandal. According to the FCA Final Notice, Barclay's failure to learn its lessons and adjust its business practices. This has been one of the aggravating factors that increased the penalty. Clearly, the probability of enforcement was not considered a credible threat in the circumstances and, by the FCA's recent admission, nobody appears to have been deterred from anything or that it has learnt any lesson. ${ }^{17}$ At best, the threat of huge fines goes as far as to motivate the industry to cooperate during investigations and agree on an early settlement in the hope of getting at least the minimum discount that may be available to them. This is not deterrence. It is more accurate to say that this is an arrangement whereby market actors (and potentially future perpetrators of misconduct) buy out their freedom to continue misbehaving.

The use of Final Notices is closely connected with enforcement and the regulator's attempt to ensure that deterrence is credible. In theory, the publication of Final Notices serve to increase the visibility of the regulator's intended disciplinary and enforcement action sending the message across that certain forms of misconduct will not be tolerated and that consequences will fall heavy to future wrongdoers. In practice, Final Notices can backfire. The Court of Appeal's judgment in the case FCA v Macris [2015] EWCA Civ 490, which was handed down on 19 May 2015 is a case in point in this regard. The case concerns the giving of statutory enforcement notices to J P Morgan Chase Bank NA in relation to the involvement of the latter in 'London Wale' trades and the identification of Mr Macris. The Court of Appeal ruled that the FCA should have treated Mr Macris as a third party for the purposes of section 393 of FSMA so that Mr Macris had availed himself with certain rights before the issue of the Final Notice. The Court of Appeal concluded that Mr Macris was entitled to refer the Final Notice to the Upper Tribunal for a hearing as to whether the criticisms of him are appropriate. Although it is difficult to make safe projections about the future, it is clear that this decision opens a window of opportunity for other closed enforcement cases to be re-opened or for current proceedings to be disrupted by individuals asserting their third party rights.

Enforcement can also backfire in a different way namely by creating bad press for the FCA. In its attempt to ensure that imminent enforcement action is loud enough to be considered a credible threat against the person who is subject to investigations, the regulator may be tempted to inflate the number of allegations against that person or it may even publish press statements that do not necessarily offer an accurate depiction of the case at stake. These scenario do not lie in the sphere of fantasy. For example, in Angela Burns v FCA [2015] UKUT 0252 (TCC) (FS/2012/0024), the FCA was successful, however the Upper Tribunal criticised the FCA for its unsatisfactory submissions on some points and for failing to reassess its position in the light of the fact that six out of its ten allegations had failed and out of the four allegations that were successful, three were upheld only to a limited extent. In Bayliss and Co (Financial Services) Ltd and Clive John Rosier v FCA [2015] UKUT 0265 (TCC

\footnotetext{
17 Commenting on the recent FRONTEX investigations, T. McDermot declared that 'still lessons are not being learnt' '[a]nd there have been all too many examples - in both the retail and wholesale space - to reinforce that view.' T. McDermot, 'Learning the Lessons of the Past as an Industry' (Speech, FCA Enforcement Conference: Our Part in Changing Culture, 2 December 2014) [available at: http://www.fca.org.uk/news/speeches/learning-the-lessons-of-the-past-as-an-industry].
} 
( $\mathrm{fs} / 2013 / 0004$ and 005) the FCA was criticised inter alia about its handling of the press statement, which was sent to selected media outlets along with the decision notices issued to Bayliss and $\mathrm{Mr}$ Rosier. The Upper Tribunal noted that the FCA press statement contained inaccuracies and that it failed inter alia to emphasize the tentative nature of those notices. Although the FCA was successful in both occasions, the poor handling of the enforcement procedure does not aid the good reputation of the FCA as a regulator whom the industry can trust and cooperate with. This is not a trivial matter as both trust and cooperation are key for industry enrolment and long term behaviour modification.

A conclusion to be drawn out of the analysis so far is that, thanks to the increased emphasis on enforcement, the FCA is making itself more visible and loud but, despite this visibility, it is doubtful that the FCA is doing better in deterring future misconduct. Visibility is neither enough nor critical in securing the credibility of deterrence. Below, I consider three further aspects of regulatory strategy that impact on the credibility of deterrence: The regulator's ability to attain a congruence of minds and congruence of hearts and its capacity to come across as a credible enforcer.

\section{Rethinking the parameters that make deterrence credible}

\section{(a) Deterrence is not credible, unless there is a congruence of ' $m$ inds'}

Deterrence cannot render long-term consistent results unless the business culture of the firms demonstrates a congruence of 'minds' between the regulator and the regulated industry about key problems and priorities. This idea is hardly new. In fact it is embedded in the very nature of both positive and negative deterrence strategies. While in the former case, this congruence of minds is the product of an effortless and voluntary endeavour to understand each other's rationalities, in the case of negative deterrence this meeting of minds is enforced. Getting to congruence of minds calls for conversional capabilities and focus on culture. The Treating Customers Fairly Initiative (TCF) is a good example of how the FCA and, before the FCA, the FSA have been trying to embed conversational regulation and culture in their attempt to deter future misconduct. ${ }^{18}$

TCF asks the industry to work out what practices guarantee fair treatment for clients in a manner that is attuned to the policy goals and priorities of the regulator. These goals reflect Principle 6 (customers' interests) of the FCA Principles for Businesses, according to which "a firm must pay due regard to the interests of its customers and treat them fairly" and they are are encapsulated in the following six TCF outcomes: ${ }^{19}$

"Outcome 1: Consumers can be confident that they are dealing with firms where the fair treatment of customers is central to the corporate culture.

Outcome 2: Products and services marketed and sold in the retail market are designed to meet the needs of identified consumer groups and are targeted accordingly.

Outcome 3: Consumers are provided with clear information and are kept appropriately informed before, during, and after the point of sale.

\footnotetext{
18 On TCF see generally A. Georgosouli, 'The FSA's 'Treating Customers Fairly' (TCF) Initiative: What is So Good About it and Why It May Not Work' (2011) 38 (3) Journal of Law and Society 405-427.

19 FSA, Treating Customers Fairly -A Guide to Management Information (2007) [available at http://www.fca.org.uk/ firms/being-regulated/meeting-your-obligations/fair-treatment-of-customers.pdf.].
} 
Outcome 4: Where consumers receive advice, the advice is suitable and takes account of their circumstances.

Outcome 5: Consumers are provided with products that perform as firms have led them to expect, and the associated service is of an acceptable standard.

Outcome 6: Consumers do not face unreasonable post-sale barriers imposed by firms to change product, switch provider, submit a claim, or make a complaint."

TCF embraces self-regulation and assumes that the members of the regulatory community are capable of working out for themselves the public standards that ought to govern their relationships. It is not a new set of secondary legislation. It is a guidance that reflects key elements of the UK regulator's strategy in the retail financial sector. The outcomes that firms are expected to deliver are communicated through informal means as, for example, Policy Statements ("PS") and "Dear CEO Letters." From this, however, it does not follow that this otherwise informal guidance has no bearing on the taking of enforcement action since the TCF outcomes echo the FCA Principles for Business and other legally binding Handbook provisions. ${ }^{20}$ The proactive and reactive nature of the measures that comprise TCF have been discussed elsewhere and they will not be here reiterated. Instead, the remaining of this section focuses on the discursive practice that goes in hand with these measures. ${ }^{21}$

Long-term cultural change is arguably impossible without industry engagement. The latter is deemed essential so that regulatees become more cognizant of their responsibilities and more sophisticated in sensing what TCF requires even in the presence of new or unforeseen circumstances. Ideally, industry engagement should be self-initiated. There are benefits to be gained out of voluntary industry engagements. Regulatees who enjoy the discretion to decide how best to proceed in their attempt to incorporate TCF into their business culture are believed to be more likely to view TCF as reasonable and thus worthy of compliance. In the past (and to a large extent even today), the UK regulator encouraged this by offering to firms a "regulatory dividend" in the form of less scrutiny, as an incentive to make them behave well demonstrating essentially that customer interests were central to the corporate culture of the business in question..$^{22}$ Like its predecessor, the FCA follows this approach but it does not rely entirely on the initiative of senior managers to ensure that the business culture of their firm is consistent with TCF. Tools like the FCA's 'Culture Framework' (CF) and 'Management Information' (MI) are deployed to help senior managers keep things in perspective, while at the same time making it possible for the FCA to get a more accurate view of the firm's capacity to deliver TCF outcomes. ${ }^{23}$ The FCA supervises and monitors the implementation of these tools engaging the industry in an on-going dialogue where perceptions are questioned, challenged and where necessary revised.

\footnotetext{
${ }^{20}$ E. Ferran, 'Regulatory Lessons from the Payment Protection Insurance Mis-selling Scandal in the UK' (2012) 13 European Business Law Review 247, 259 (characterizing the TCF outcomes as "non-binding guidance").

21 For a classic exposition of the nature of conversational regulation see J. Black 'Regulatory Conversations' (2002) Journal of Law and Society 163-196 and 'Talking about Regulation' (1998) Public Law 77-105. For a criticism see, A Georgosouli, 'Regulatory interpretation: Conversational or Constructive?' (2010) 30 (2) Oxford Journal of Legal Studies 361-384.

22 A. Georgosouli, C. Russo and P. Rawlings, Regulation of Financial Services: Aims and Methods (CCLS Research Paper, April 2014) [available at: http://www.ccls.qmul.ac.uk/docs/research/138683.pdf.] (noting that this policy reflected an assumption that the vast majority of firms had the intention to treat their customers fairly and that the majority were willing to engage openly and positively with the regulator and arguing that both assumptions proved to be naïve in reality). 23 FCA, TCF Culture, (Apr. 5, 2013) [available at: http://www.fca.org.uk/firms/being-regulated/meeting-yourobligations/fair-treatment-of-customers/Culture; FSA, TCF - Towards fair outcomes for consumers (2006) [available at: http://www.fca.org.uk/static/fca/documents/fsa-tcf-towards.pdf.].
} 
Investigations and enforcement also provide channels of communication and in that sense they are instrumental in forging a congruence of minds. The regulator's enforcement strategy goes beyond penalizing unacceptable forms of business conduct. Like supervision, it targets culture securing at the same time some form of redress or other remedy for the aggrieved parties. The UK regulator tends to see the offender's non compliance as an opportunity for the offender to reflect on what went wrong and make things right by taking remedial action, revising processes, practices, and ultimately its corporate culture. ${ }^{24} \mathrm{~A} \& \mathrm{~L}$ demonstrates this quite well. $\mathrm{A} \& \mathrm{~L}$ was ordered to pay the biggest fine for serious failings in the selling of PPI pre-crisis. However, A\&L also agreed to implement a customer contract programme overseen by third-party accountants. Under this programme, A\&L undertook, amongst other things, to contact all customers that purchased PPI in conjunction with an unsecured loan, to review its policy in respect of product information that was sent to these customers, to review any rejected complaints and claims, and to pay redress where appropriate.

More generally, the desirability of enforcement action is assessed in light of its likely impact on the industry's capacity to develop patterns of self-regulation. It is forward-looking in the sense that it aims to educate the regulated industry and to encourage a change of culture. Being partly premised on negotiation, the enforcement procedure itself creates opportunities for the alleged offender to deliberate with the regulator, become cognizant of its failure to comply, remedy any wrongdoing, and revise its business practice where appropriate.

Discursive capabilities have their own limitations in promoting the requisite congruence of minds. ${ }^{25}$ Given the limited space available, I will not give a comprehensive account of these limitations but for expository purposes I would like to note only two of them. The first one concerns culture. Culture becomes a focal point for deterrence because this is where to look at in order to find out whether the objectives, priorities and worldviews of the industry match those of the regulator. The expected benefits to gain out of placing emphasis on culture should not be blown out of proportion. At least in part, the efficacy of the regulator to instigate cultural change depends on the willingness of the firms to genuinely engage with the regulator and - when challenged - to reflect on the soundness of their respective culture in order to amend business practices where appropriate. Persistent industry regression leaves little scope for optimism. ${ }^{26}$

Retail financial firms are not charities working in the interests of customers. They are profit-driven institutions. A business culture that ends up reflecting both the profit-driven character of the business and the firm's perceived commitment to public policy goals, like fair treatment for customers, is bound to be self-defeating because it constitutes a contradiction in terms. One must take priority, and quite intuitively this will have to be profit. Otherwise, the business will not be able to survive. This is not to say that no good can come out of business culture. It can, but in all probability, it is going to be less than we are inclined to think. Profit-making considerations confine

\footnotetext{
${ }^{24}$ This approach survived the upheaval of regulatory reform in the aftermath of the recent financial crisis and it is now crystallised in various dispute resolution provisions of the FCA Handbook.

25 On the limitations of conversational regulation see A. Georgosouli, 'The Revision of the FSA's Approach to Regulation: An Incomplete Agenda?' (2010) Issue 7 Journal of Business Law 599 at 604 and 'The Nature of the FSA's approach to regulation' (2008) 28 Legal Studies 119 at 135.

${ }^{26}$ See discussion below at pages 9-12.
} 
how far the regulator can go in aligning the goals and priorities of the industry with those of the regulator and, by implication, to what extent it is possible to rely on business culture. Accordingly, when relying on business culture a healthy dose of pragmatism is called for to make the credibility of the deterrence policy in the first place.

Quite apart from the fact that that conversational capability breeds conditions of regulatory capture as a result of the close and on-going interaction of the regulator with the regulated industry, it is also liable to create another side effect. Market actors usually score high when asked to demonstrate that they endorse the priorities and aims of the regulator, while in practice exploiting every opportunity for contravention. The widespread practice of creative compliance demonstrates how well regulatees do in keeping appearances by engaging in a 'box ticking' exercise in their dealings with the regulator. ${ }^{27}$

To conclude, congruence of minds is good but is not enough. The credibility of deterrence requires more than getting the members of the regulatory community see each others' rationalities. As I argue below, it also calls for congruence of hearts.

\section{(b) Deterrence is not credible, unless there is a congruence of 'hearts'}

While conversational capacities harness cooperation between the regulator and the industry, the creation of a common language and increased familiarity with the rationalities of others are not enough on their own to ensure that the commitment of the industry to deliver the regulator's agenda is actually genuine. Conversational capacity goes as far as to create a meeting of minds. It does not warranty a meeting of hearts. This is crucial but very hard to achieve as this meeting of hearts presupposes confidence that regulation is fair to all parties affected. Part of the problem derives from the presumably elusive nature of the principle of fairness in regulation. The vagueness of fairness means that regulators and policy makers are bound to encounter insurmountable practical difficulties in their attempt to improve the fairness of a particular regulatory regime. As it is commonly thought, fairness lacks a generally accepted definition and as a result it cannot be measured or accounted for in any tangible kind of way. The definitional argument has a kernel of truth but it is not entirely convincing.

Quite apart from the fact that it is premised on the absurd expectation that for every principle, norm or doctrine there must always be an ex ante and ideally universally accepted understanding for otherwise public governance cannot work, this position seems to downplay the fact that the members of the regulatory community are actually furnished with all the linguistic and interpretive tools that are necessary in order for them to make sense of abstract terms and thus to overcome any definitional difficulties in real life situations. ${ }^{28}$ Sometimes they get the interpretation of principles like fairness right. Sometimes they get it wrong. It may also be the case that they take

27 D. McBarnet and C. Whelan, 'The elusive spirit of the law: Formalism and the struggle for legal control' (1991) 54 (6) Modern Law Review, 848-873.

${ }^{28}$ A. Georgosouli, 'Regulatory interpretation: Conversational or Constructive?' (2010) 30(2) Oxford Journal of Legal Studies; 'Judgement-led regulation: Reflections on data and discretion' (2013) 14 Journal of Banking Regulation 209-220 at 215 (providing brief examples). For a more comprehensive discussion in the literature of the philosophy of mind see notably $D$. Davidson, 'What thought requires' Essay 9 in Problems of Rationality 135 (USA: Oxford University Press; 2004) and 'Coherence theory of truth and knowledge' Essay 10 in Subjective, Intersubjective, Objective 137 at 138-140 (USA: Oxford University Press; 2001). 
advantage of this interpretive practice to manipulate it in a way that serves their own interests. The fact remains that although they tend to disagree on the best interpretation of fairness they are still able to tell with some confidence when in the circumstances a certain interest group has been fairly treated and when it has not. For instance, it is hard to argue that consumer groups are treated fairly when they do not have the chance to participate and indeed to have their voice heard during public consultations about the introduction of substantial reforms to the existing regulation of the retail financial sector namely reforms that are going to have a major impact on them. To cut a long argument short, the practical difficulties that are associated with the vagueness of the principle of fairness should not be blown out of proportion and, in any case, they do not offer a valid reason for abandoning the idea of harnessing fairness capabilities in regulation all together.

The importance of fairness in regulation seems to find support in current literature of compliance and enforcement. For example, in her critique of responsive regulation, Karen Yeung argues that we should not overlook the constitutional values of proportionality and consistency in enforcement, which are themselves rooted in the right to a fair and equal treatment. ${ }^{29}$ With respect to enforcement, the principle of proportionality, for instance, requires that the regulator's action must be commensurate to the seriousness of the issue at hand. Crucially, the test of proportionality that Yeung proposes is not functional in nature. Rather it is substantive going beyond determinations that have as a point of reference the goal of effective future compliance without any due consideration to the nature and seriousness of the defendants' violation.

A conclusion to be drawn out of this analysis is that if we wish to cement the credibility of deterrence by winning the hearts of the industry, then we must find ways to improve the procedural fairness of the regulator's strategy of compliance and enforcement. This is true but it tells half the story. Regulation promises benefits but comes with burdens and real life suggests that the regulator's capacity to harness a sense of fairness in the sharing of burdens (substantive fairness) matters as well. Let's take the example of the recent experience with the financial mis-selling saga in the UK. ${ }^{30}$ The reaction of the industry reveals a more general concern with the fairness of the way in which the regulation of financial mis-selling allocates burdens among financial services and products providers and their customers.

Following the long British tradition of self-regulation as the main conduit of cultural change, the Financial Services Authority initially internalised self-regulation into a government-based hybrid scheme of responsive regulation. It tried to engage with the industry in order to ensure that customers are treated fairly but the industry's commitment to attune its business culture with the goals and priorities of the regulator's agenda was nothing but genuine. The large number of Payment Protection Insrance (PPI) complaints about mis-selling practices that were referred to the Financial Ombudsman Service (FOS) and the significant discrepancy in outcomes between PPI complaints that were handled by firms (a majority of which were rejected) and those that were

\footnotetext{
${ }^{29}$ B. Morgan and K. Yeung, An Introduction to Law and Regulation: Texts and Materials (Cambridge: Cambridge University Press; 2007) 201-202. For a more comprehensive discussion see K. Yeung, Securing Compliance (Oxford: OUP, 2004).

${ }^{30}$ The articulation of the principles of fairness in regulation falls beyond the scope of this chapter, however, one possibility is to follow the contractualist tradition in moral philosophy and argue that burden sharing must adhere to principles of justice that regulatees are taken to be able to justify to each other. On the contractualist school of thought see notably $T$. Scanlon, What We Owe to Each Other (Harvard University Press, 2000).
} 
referred to the FOS gave a very disappointing picture of the industry's commitment. ${ }^{31}$ More recently this became evident in the industry's attempt to challenge the FSA's decision to take enforcement action in view of the industry's failure to take into account FOS decisions in handling customer complaints contrary to the regulator's expectation as it was communicated in a Policy Statement $\left(\right.$ "PS"). ${ }^{32}$ The industry eventually lost its case, but, in the course of bringing the action, several firms put on hold the handling of nearly all PPI complaints. This caused significant delays in the processing of financial redress to the victims of financial mis-seling. Most importantly though, it aggravated the situation in the eyes of the UK regulator and eroded any past attempts to build trust. The grounds of this deep resentment continue to keep momentum. For example, the length of time of the legal proceedings of the Keydata Investment Services case demonstrates how determined the industry continues to be in seeking to cause delays and more generally derail the regulator's endeavours. ${ }^{33}$

Judging from the history of PPI mis-seling, we can tell with some confidence that financial services providers fell short from complying with best practice in their dealings with customers. However, we should not be quick to vilify them or, indeed, to jump to the conclusion that their reluctance to commit to the FSA's agenda was capricious. Clearly, they felt that they were made to bear more burdens in the delivery of fair treatment for clients than they ought to. For some financial firms, the burdens took the form of additional costs as a result of legal uncertainty given the informal nature of the Policy Statements through which the regulator communicated its expectations. For others, the burdens took the form of additional costs as a result of the eventual transformation of conduct of business requirements into a detailed set of legally binding rules -a development that also increased the risk of litigation. Yet for others, compliance with the relevant regulation meant investing time and resources to take action for matters that, in their view, were not their responsibility to do so most notably the review of complaints handling policies even in relation to transactions for which they had never received customer complaints.

Taking things forward, the FCA's policy of enforcement is not perfect but by and large it is consistent with constitutional principles like procedural due process, proportionality and equal treatment. Accordingly, in relation to the improvement of procedural fairness, the challenge at hand is not so much ensuring the constitutionality of the FCA's compliance and enforcement but rather dealing with the more mundane issue of quality assurance in the handling and effective execution of investigations and enforcement proceedings, since procedural failings of that type offer grounds for judicial review. Cases like Angela Burns v FCA which was discussed above reveal that this is already a

\footnotetext{
${ }^{31}$ A. Georgosouli 'Payment Protection Insurance (PPI) Misselling: Some Lessons from the UK' (2014) 21 (1) Connecticut Insurance Law Journal 261-288; E. Ferran, 'Regulatory Lessons from the Payment Protection Insurance Mis-selling Scandal in the UK' (2012) 13 European Business Organisation Law Review 247.

${ }^{32} \mathrm{R}$ ex rel. British Bankers Association v FSA [2011] EWHC (Admin) 999.In its judicial review action the industry made three principal contentions. The first was that PRIN are not actionable at a suit by a private person in view of the wording of old section 150 of the FSMA 2000. Accordingly, they could not give rise to redress obligations. The second was that regulatory principles could not conflict with or augment specific rules. Finally, the third contention was that the existence of an alternative statutory collective redress scheme precluded the FSA from taking the action set out in the Policy Statement.

33 S.O. Ford, M.J. Owen, P.F Johnson v FCA [2015] UKUT 0220(TCC) Case numbers FS/2014/0012, FS/2014/0013, FS/2014/0016 [available at http://www.tribunals.gov.uk/financeandtax/Documents/decisions/Ford-Owen-Johnson-v-FCAdecision.pdf]. See further, FCA, FCA Press Release (26/5/2015, last modified 2/6/2015) 'The FCA has today published Decision Notices in respect of three former members of Keydata's senior management: Steward Ford (former chief executive), Mark Owen (Former Sales Director) and Peter Johnson (Former Compliance Office)' [available at https://www.fca.org.uk/news/fca-published-decision-notices-three-former-members-keydatas-senior-management].
} 
source of concern. ${ }^{34}$ The FCA must now manage a growing number of investigations and enforcement but resources have not been increased to match up this trend. There is no magic solution to this problem. Either the FCA will have to reduce the number of cases that is handling concurrently or secure more public resources to train its staff and to fund its operations.

Harnessing a sense of substantive fairness is far more challenging. In any case, there are steps that can be taken towards this direction. To return to the PPI mis-selling saga, obviously, the FCA need not agree with the industry's understanding to what would amount to fair burden allocation to ensure that customers are treated fairly. All the FCA needs to do and in part already does is to challenge industry perceptions about fair burden allocation in a structured, consistent, time efficient and monitored fashion. This can be done by making more frequent use of rules which come with the requirement 'to comply or explain' and ad hoc communications as part of the supervisory process whereby FCA staff challenges the perceptions of fairness that are embedded in the business culture of the financial services and products provider in question. What is perhaps missing is the implementation of a comprehensive medium and long term 'follow up' process through which the FCA would return back to past wrong-doers to monitor how well they are doing in adhering with rules in an on-going basis rather than falling back to an attitude of treating the matter of compliance as an 'one-off thing'.

Asking financial services providers to bear the cost of customer protection is unlikely to be acceptable to them, unless the FCA demonstrably seeks ways to alleviate or otherwise reduce this cost. Clearly financial services and products providers of different size, expertise and level of sophistication have different capabilities to manage the cost of customer complaints due to alleged cases of financial mis-selling. The FCA must acknowledge this and be prepared to offer a helping hand' by providing, for example, guidance and expert advice to small size firms on what they ought to look for while reviewing customer complaints. Financial literacy can also reduce costs. For example, financially literate customers are more likely to be vigilant of misconduct and more likely to take initiative and protect themselves going down the route of the internal complaints procedures so that financial firms do not have to review past financial transactions to spot any instances of misconduct on their behalf. Like its predecessor, the FCA is taking measures to improve the financial literacy of the public but basic legal literacy is not included in the agenda. ${ }^{35}$ This is to be regretted as quite often consumers do not take any action out of fear of the cost or due to ignorance of the available means of redress. The results have been mixed so far and if anything they indicate that more needs to be done to discourage passivity and increase awareness. ${ }^{36}$

(c) Deterrence is not credible, unless there is stakeholder confidence that the regulator is a 'credible' enforcer

\footnotetext{
34 FCA v Angela Burns [2015] UKUT 0252 (TCC), Case Number FS/2012/0024 and, in particular, paragraphs 15 and 16 [available at http://www.tribunals.gov.uk/financeandtax/Documents/decisions/Burns-v-FCA-penalty.pdf].

${ }^{35}$ Legal literacy could be harnessed in partnership with public agencies and other professional bodies and associations that are involved in the regulation of the legal profession as, for example, the Legal Services Board and the Solicitors Regulation Authority. See further discussion below at page 14.

${ }^{36}$ See, for instance, FCA Press Release 'FCA challenges firms to review approach to consumer vulnerability' (23/2/2015) [available at: http://www.fca.org.uk/news/fca-challenges-firms-to-review-approach-to-consumer-vulnerability].
} 
It is naïve to think that increasing volume of enforcement cases boost the credibility of the FCA as enforcer. In fact, the profile of the FCA as a credible enforcer can be diluted by several factors. One of them is certainly the reception of bad press. As it was discussed in a previous section of this chapter, this is already concerning due to the FCA's perceived mishandling of some of the recent enforcement cases. Historically, however, bad press seems to derive by the fact that enforcement action is not visible enough in view of the early settlement of many disputes. ${ }^{37}$ Early settlement may secure quick financial redress for the victims of misconduct but this is hardly registered in collective memory. By contrast, this lack of visibility fuels a sentiment that wrong-doers can get away because they can afford to pay the price of their wrong doing.

New section 391 (1ZB) of the FSMA 2000 was inserted into the 2012 revised version of the FSMA in order to increase the visibility of the regulator's disciplinary actions in the hope that this visibility will have the desired impact on behaviour modification. In theory, the FCA can now publish information about warning notices in certain cases but the relevant provision is complicated and drafted in such a level of detail that makes almost impossible to make a meaningful use of this option. A careful reading of the provision makes plain that the regulator must, inter alia, consult with the person to whom the notice is given. In addition, the FCA's power to publish information about warning notices is restricted by virtue of section 391(6), which prohibits the FCA from publishing information when the publication would be (a) unfair to the person against whom that action was proposed to be taken; (b) prejudicial to the interests of consumers; or (c) detrimental to the stability of the UK financial system.

The difficulties with the application of these provisions also raise two further issues. The detailed drafting of the provisions makes it easier for resentful parties to file a successful lawsuit against the FCA if they feel that their human rights have been violated. With other words there is an increased risk of legal contestation. Furthermore, the delegation of powers that is difficult or impossible to use in any sort of meaningful way is probably not a wise policy choice because the FCA is likely to be caught in a future blame game, which will be difficult to handle. There is a simple reason for this. If things were to go wrong the accusation would be that the FCA could have done something but it chose to do nothing. Limited time and resources to handle an ever-growing volume of investigations and enforcement also has its toll on the FCA's capacity to cement its reputation as a credible enforcer. The institutional complexity within which the FCA performs its functions adds up to this problem.

Experience in the UK suggests that the intensity of enforcement action varies and that it is by and large driven by the prevailing political climate. ${ }^{38}$ For example, if we look back in time a few years ago, the FSA's willingness to proceed to formal enforcement gained momentum during the recent financial turmoil, that is to say, at a time when there has been great political pressure to bring cases to court. As collective memory of the financial crisis of 2008 fades away, the regulator's commitment to formal enforcement is expected to recede. To the extent that this pattern can be attributed to political happenstance rather than a principled decision to adapt the strategy of

\footnotetext{
37 In fact, the industry is given several incentives to opt for early settlement, such as discounts and the reduction of financial penalties FCA, Decision procedure and penalties manual para 6.7 (2014) [available at: http://media.fshandbook.info/content/FCA/ DEPP.pdf.].

${ }^{38} \mathrm{~A}$. Georgosouli et al above paragraph 7.2.1.
} 
deterrence in view of changes in the market environment, differences in the intensity of enforcement implies an inconsistent policy of deterrence. In the absence of a consistent strategy of deterrence, it hard to see how the FCA can possibly convey its seriousness of intention to pre-empt members of the industry from future misconduct.

The analysis above does not provide an exhaustive account of the factors that impact on public confidence over the capacity of the FCA as a credible enforcer. Nevertheless, they highlight aspects of the deterrence policy of the FCA that call for revision and potentially reform. More public funding is required for the support the deterrence strategy of the FCA for otherwise the FCA will have to cut back on the volume of investigations and disciplinary and enforcement actions in order to ensure quality assurance in the execution of its statutory mandate. Legal reform is also recommended in order to rationalise the FCA rulebook, declutter the current institutional set up and ensure that the FCA is equipped with powers that it can actually make use of. All these are expected to reduce the time and cost of deterrence strategy but will not be enough to reinforce public confidence. Extra measures will be required to improve transparency. The FSMA 2012 lays down a sound system of accountability, which can be further improved by introducing an incentive-based performance index to assess how well the regulator does in reaching its deterrence targets. ${ }^{39}$ This is different from statistics providing numbers of lawsuits or aggregate amount of financial sanctions and penalties or financial redress secured for the victims over the years. While statistics provide data about the intensity of enforcement, the incentive-based performance index that is here proposed offers a more accurate picture of the impact of enforcement on culture modification by measuring the alignment of industry incentives with those of the regulator. The auditing of the regulator's incentive could improve the regulator's profile as a credible enforcer as long as it offers evidence-based data demonstrating that the regulator always acts having the public interest at heart.

It is not enough for the FCA to be a successful enforcer; the FCA must come across as a credible enforcer to the eyes of the beholder. A question to ask here is who the beholder is. It comes naturally to think that the beholder is the industry since the industry provides the pool of future perpetrators of misconduct namely the target group of every deterrence strategy. This notwithstanding, the perceptions of future victims matter as well. When future victims of misconduct are confident about the capabilities of the FCA as an enforcer, the profile of the FCA as a credible enforcer is fortified. Thus, it is likely to be taken more seriously by the industry. ${ }^{40}$ Moreover, the FCA has better chances to deter the industry from misconduct, when it 'deters' future victims from an attitude of apathy in respect of their right to seek compensation or other forms of remedial action and redress. This is also important because it means that future perpetrators of misconduct

\footnotetext{
${ }^{39}$ The role of misaligned incentives in contributing to the recent financial crisis has been well documented in the literature. The relevant scholarship has two limbs. On the one hand, one finds a constellation of readings on the impact of industry incentives when these are not aligned with those of the regulators. Examples here include studies on the incentive of senior bank managers to secure short-term profits or to exploit public subsidies by creating banks that are 'too big to fail'. On the other hand, one finds a growing volume of literature on the misalignment of regulators' incentives in various institutional settings as this is manifested, for example, in their tendency to withhold information from others during times of crisis See generally, M Cihak, A Demirguc-Kunt and R. Barry Johnstin, 'Incentive Audits: A New Approach to Financial Regulation', Policy Research Working Paper 6308 (The World Bank Developments Research Group Finance and Private Sector Development Team, January 2013) with further references to the relevant scholarship.

40 Although theoretically a danger here is that of a complacent regulator as there is no incentive to improve performance when the current and future victims of misconduct or perhaps other stakeholders no longer put pressure on the regulator to do a better job.
} 
will have to think the prospect of the credible reaction of future victims of their misconduct in addition to the prospect of public enforcement before considering behaving 'badly'. Of course, it would be absurd to suggest that the FCA ought to deter future apathy by 'punishing' existing victims who do not take initiative to receive the legal protection that they are entitled to. The only route seems to be changing consumer/customer culture through financial literacy and other consumer awareness initiatives. The FCA and other agencies like for example the Money Advice office do this already, although these initiatives may not be receiving enough press. In any case, there is no warranty that this will continue in the future. Unlike the FSA, the FCA must act at a time of austerity. Furthermore, it is not legally mandated by the FSMA to increase 'public awareness'. As a matter of fact, the FCA is legally mandated to protect consumer interests by focusing on competition rather than financial literacy and education. ${ }^{41}$

\section{Conclusion}

It is hard to argue against deterrence. Despite the fact that the implementation of deterrence strategies is a challenging on-going process, everyone seems to accept that prevention is better than cure. Accordingly, the question to ask is how the regulator can do a better job in pre-empting future misconduct. It is widely accepted that deterrence is credible unless it is visible and that visibility requires emphasis on enforcement and harsh sanctions so that the industry takes it seriously and behave itself accordingly. In this chapter, I argued that, although enforcement (or rather the threat of it) is an undisputed incentive-modifying tool, the focus on enforcement is misplaced. Credibility is not secured by simply scaring regulatees off in the gloomy prospect of tough consequences as a punishment for their misbehaviour. Deterrence is not credible, unless there is a congruence of 'minds' and a congruence of 'hearts' between the regulator and the members of the industry to whom deterrence measures (including but not limited to enforcement) are targeted. Last but not least, credibility calls for measures that strengthen the profile of the regulator as a credible enforcer.

Enforcement or rather the threat of it plays a role in attuning industry incentives with those of the regulator but we are likely to do a better job in strengthening the incentive-alignment capacity of the existing regulatory approach to deterrence if we look elsewhere and in particular into issues concerning the organisational structure of the financial services provider and its regime of corporate governance. This can be done through the development and implementation of on-going incentive audits with respect to remuneration, executive compensation, accountability and legal liability in order to identify and monitor sources of conflicts of interest, moral hazard, organizational complexity, opacity and other features that affect the incentive structure that informs the setting of priorities and decision-making within these firms. Industry incentive audits are here recommended for an additional reason. The FCA is placing increasing emphasis on culture but culture cannot be enforced and is hard to regulate. Incentive audits can be the antidote to the perceived limitations of enforcement to modify culture to the extent that it is designed to spot triggers of incentive misalignment as these emerge. Incentive-based regulation is not a panacea but it pledges to add a

\footnotetext{
41 There is however a window of opportunity to argue that financial literacy programs are still legally mandated to the extent there is empirical evidence supporting the view that financial literate consumers improve competition in the financial services sector.
} 
5 October 2015. CCLS Working Paper (research work in progress). Please do not cite without author's permission.

more tangible and pragmatic dimension to the existing deterrence strategy. This is reason enough to merit consideration. ${ }^{42}$

${ }^{42} \mathrm{M}$. Cihak et al above at 12-13 (advocating for incentive-based regulation as a regulatory approach that pledges to be more dynamic and forward looking and to treat the underlying incentive issues that undermine regulatory effectiveness; not just the symptoms of regulatory failure). 